\title{
TRANSLATION PROCESS RESEARCH AS INTERACTION RESEARCH: FROM MENTAL TO SOCIO-COGNITIVE PROCESSES
}

\author{
Hanna Risku \\ Karl-Franzens-Universität Graz (Austria) \\ hanna.risku@uni-graz.at
}

\begin{abstract}
The main methodological approaches used in cognitive translation process research have hitherto been inspired by methods originally developed in the behavioural sciences, especially psychology. This article contends that mainstream experimental research in laboratory settings needs to be complemented with other methodological approaches such as qualitative, ethnographic research in order to be able to account for the situated, embedded and extended aspects of cognition - as described in current cognitive science approaches. In addition, it presents the empirical research design and initial results of an ethnographic field study into the socio-cognitive aspects of translation. The results show the complexity of the social network involved in the observed case of freelance translation, the tendency of the translator to externalize parts of the process and thus transform the internal processing into an interaction with self-produced outer stimuli-thereby reconfiguring the cognitive space-and the existence of distinct, iterative interaction patterns that stand out as behavioural and cognitive routines in the way the translator works.
\end{abstract}

\section{Kurzreferat}

Die zentralen methodologischen Ansätze der kognitiven Translationsprozessforschung orientierten sich bisher an jenen Methoden, die ursprünglich im Rahmen der Verhaltensforschung, allen voran der Psychologie, entwickelt worden waren. In diesem Beitrag wird argumentiert, dass die etablierte Tradition der experimentellen Laborforschung mit weiteren methodologischen Herangehensweisen, etwa dem ethnographischen Forschungsansatz, ergänzt werden sollte. Entsprechend der gegenwärtigen Auffassung in der Kognitionswissenschaft bietet eine derartige Erweiterung die 
Möglichkeit, dem Konzept der situated, embedded und extended cognition Rechnung zu tragen. Des Weiteren werden in diesem Beitrag das empirische Forschungsdesign sowie erste Ergebnisse einer ethnographischen Feldstudie zu soziokognitiven Aspekten von Translation beschrieben. Die Beobachtungen einer freiberuflichen Übersetzerin offenbaren zunächst die Komplexität ihres sozialen Netzwerkes. Zudem wird die Tendenz der Übersetzerin deutlich, Teile des Arbeitsprozesses zu externalisieren, wobei interne Verarbeitungsprozesse zu Interaktionen mit selbst generierten Artefakten umgewandelt und kognitive Räume somit neu konfiguriert werden. Nicht zuletzt wird die Existenz verschiedener, iterativer Interaktionsprozesse veranschaulicht, die spezifische Verhaltens- und Denkmuster der Übersetzerin darstellen.

Keywords: Translation process. Interaction. Situated, embodied and extended cognition. Ethnography. Network. Workplace.

Schlagwörter: Übersetzungsprozess. Interaktion. Situierte, verkörperlichte und erweiterte Kognition. Ethnografie. Netzwerk. Arbeitsplatz.

Manuscript received on April 2, 2013 and accepted on September 25, 2013. 


\section{Introduction}

The paper begins with a brief description of the goals and methodological development of the study of cognition in translation. The main experimental path in cognitive translation studies is outlined, and a complementary, ethnographic studies approach is suggested in order to be able to account for the situated, embedded and extended aspects of cognition, as described in current cognitive science approaches. The empirical research design and first results of a field study into the socio-cognitive aspects of translation are also presented.

The case described in this paper forms part of preparatory research for the "Extended translation: Socio-cognitive translation processes in the workplace" (ExTra) project that is being carried out by the Translation: Cognition and Cooperation (TCC) Research Group in the Department of Translation Studies at the University of Graz from 2014 to 2016. ${ }^{1}$ Given the growing appreciation of the need to recognize the extended, embodied and situated nature of human cognition, this project has been specifically designed to take an extended approach to capturing and exploring some of this complexity and heterogeneity. Translation processes are examined in terms of translation networks, actors and environments. Our aim is to acquire rich descriptions of individual cases which can then be related to each other-using a methodological approach which could be labelled as an ethnographic, multi-case method and includes qualitative interviews and participant and non-participant field studies. These different forms of analysis are inspired by diverse, yet compatible theoretical frameworks and will collectively help to create a comprehensive picture of the dynamics and the embodied, extended and situated cognitions involved in translation processes.

In line with the concept of "theory as process" (Glaser \& Strauss 1974), the case described in this paper is the first field study for this project and allows us to generate initial results as data-oriented hypotheses. In addition, it serves to test the ethnographic viability of the data acquisition methods

1. This research is funded by grant P26332 from the Austrian Science Fund (FWF). 
chosen and the adequacy of the method of data analysis. This first case also serves to explore the practical challenges of entering and carrying out research in the field (see also Ehrensberger-Dow, this volume) and in the specific translation situation: a freelance translator working directly for clients, not for translation agencies. However, these methodological considerations do not form the subject of this paper, which instead presents the first preliminary results for the project.

\section{The experimental and the ethnographic path}

A central goal of cognitive science approaches in translation studies is to model the cognitive processes in translator actions. The ultimate aim of such modelling enterprises is to establish a deeper understanding of how translations are produced, thus identifying the main factors on which the translation process depends and how these factors influence each other. Even though the end product, a translation, is the indisputable main goal of the process studied, from a "translator studies" perspective (Chesterman 2009), the research focus lies explicitly on the translation process, and less on this translation as the end product. There is a considerably strong consensus that analysing an end product will not reveal the factors that made it the way it is - to uncover these, we have to analyse the actual process itself and the factors that influenced this process (and, in our case, lead to the translation product).

The main methodological approaches used to make these processes and factors visible and analysable in cognitive science approaches in translation studies or cognitive translation studies have hitherto been inspired by methods originally developed in the behavioural sciences, especially in psychology. The methodological challenges of this line of process research include establishing an exact definition of the variables to be studied, hypothesizing a correlation between them, being able to manipulate a particular variable, setting up an experimental and a control sample/group, and analysing a statistically sufficient amount of data or subjects to verify or falsify the hypotheses. Due to the need to control the confounding variables, the empirical research is mostly carried out in a laboratory setting.

In such approaches, the persons translating a text specifically chosen for the study are observed, primarily using the thinking-aloud method, retrospective interviews, keylogging, and/or eye-tracking. This line of methodological development can be regarded as the mainstream of translation process research. It has been the subject of considerable constructive criticism in the last decades, mainly with regard to the need to establish a control group, argue for the choice of participants (laymen, learners, translation 
graduates, working translators), define the necessary criteria for their inclusion as participants, control the variables, include other data than just verbal, introspective data, involve a sufficient amount of data or subjects, and carry out other preparations to make sure the study actually measures what it is supposed to measure. Thus, this line of criticism and the subsequent development of the research designs are aimed at the fulfilling of the requirements set for classic scientific experiments. This development follows a positivist line of thinking, relying on a quantitative analysis of data as required in controlled experiments. In my view, these improvements were (and still are) necessary to correctly define the scope of the experimental data and the status of the results as well as to unlock the full potential of the mainstream experimental path.

However, my main point in this article is that we will also need other methodological paths of inquiry to model the cognitive processes in translation and to establish a deeper understanding of how translations are produced. Present cognitive scientific views of human intelligence, such as the situated, embodied and extended cognition approaches (see, e.g., Suchman 2007, Clark 2008, Clark \& Chalmers 1998), suggest that cognitive processes are context-dependent, i.e., they are dependent on and partly constituted by the social and physical environment in which they are carried out. Cognition is made up of parallel processes like bodily movements and neurological activity, action and perception, externalization and internalization inside and outside the mind (the leaky, situated mind; Clark 1997). Furthermore, these processes are path-dependent processes that do not conform to stable rules but instead depend on the point in time in which the individual cognizers happen to be in the cognitive and environmental dynamics (Clark 1997:204ff). Cognition itself is heavily dependent on the sequence of prior learning and doing (Elman 1994). Its context- and path-dependency suggests that we will actually also have to study translators in their authentic, personal, historically embedded environments and translation situations if we want to be able to describe the cognitive process-i.e., if authentic translation processes are to be included in the research object.

Translation process research has hitherto focused strongly on the mental processes of individuals in isolation, while situated and embodied cognitive science approaches describe the situation as part of the thought process, and cultural artefacts as cognitive scaffolds used for support in cognitive activities (Clark 1997, Clark 2008, Hutchins 2010). Accordingly, one of the goals of the present project is to investigate and understand the relevance and consequences-in terms of practical decisions in translation process research 
projects-of translation not being an internal symbol-manipulation process that is independent of time, place and history. The research design takes into account those recent professional developments that can be characterized as a move towards a computer-assisted network economy (Abdallah 2010, Risku 2009, Risku \& Dickinson 2009, Abdallah \& Koskinen 2007). The research focuses on the interaction between translators and their environments and the resulting dependencies. In doing so, it addresses heterogeneous areas like cooperation with subject matter experts and colleagues, terminology management and contacts with customers. In essence, this perspective enlarges the object of process research, which can then be styled as extended translation, i.e., as a form of coupled system between human organisms and external entities. Thus, in addition to the experimental, quantitative line of empirical research, we will also need descriptions of translatorial cognition and action in its dynamic and social setting.

\section{Exploring the methodological consequences}

The contemporary debate on the theoretical consequences of the current cognitive scientific approaches to the concepts used in cognitive translation studies is lively and productive (see, for example, Muñoz 2013, Martín de León 2013, Risku 2010). Indeed, it would seem that a lot of rethinking, reorientation and restructuring need to be done to take the cognitive scientific developments into account in our theoretical work. The need for innovation would seem to be even more pressing on the methodological level: Scholars of cognitive translation studies have only just started to develop and pilot new research designs that have the potential to cope with the overwhelming changes in research methodology needed to study situated, embodied and extended cognition.

The present article is a report on one of my first tentative steps in exploring the practical possibilities of doing justice to the research object-cognition as described in the situated, embodied and extended cognition approaches-in the practical decisions of empirical research design. With this aim in mind, I have placed special emphasis on studying factors that have not been the centre of attention in translation process studies in recent decades, such as the social, historical and environmental embeddedness of cognition in translation. The ethnographic path lends itself nicely to such purposes. Here, qualitative field studies with participant observations are conducted to reveal an internal view of how meaning is constituted by the participants themselves in their own particular situations. In contrast to the quantitative, experimental path described above, the methodological challenges of this line of translation 
process research include being able to describe or at least approximate the perspective of the participants in their authentic situations of action, and being able to show how they construct meaningful action and structure the research object. Accordingly, the object of research can be described as the "methodology" of everyday cognition (as emphasized in the ethnomethodology approach; Garfinkel 2002).

One of the essential differences to the controlled experiment path is that the factors to be studied are not defined and determined exactly prior to empirical inquiry; they are identified through the empirical research itself. With recourse to prior research (both theoretical and empirical), there will be prior assumptions regarding the kind of factors that will probably be relevant. These assumptions are necessary to allow some structuring of the research object prior to empirical inquiry in order to decide on the data sources to be included. However, the aim here is to approach the research object as something "other", so that previously unknown phenomena can become visible through empirical observation and analysis (Hoffman-Riem 1980). Thus, the basic hypothesis is that the research object will include factors that were not thought of when planning the research. The researchers are like anthropologists entering partly unknown territories and cultures, trying to find out how the research object is structured in the first place.

Again, in contrast to controlled experiments, ethnographic research has developed a systematic procedure not just for testing but also for developing hypotheses. According to the "theory as process" approach (Glaser and Strauss 1974), first data-oriented hypotheses are generated through the first field study or studies. These hypotheses will be expressed using labels that are as close to the data as possible in order to avoid premature, undue generalisation. They also influence the choice of the next case or cases to be studied (a procedure called theoretical sampling). The subsequent cases are again observed and analysed in a data-oriented manner, so that new hypotheses can be generated, and the prior hypotheses can be tested and adapted through systematic comparative analysis. This procedure of expanding the field, data-oriented and comparative analysis, and generating and testing hypotheses is repeated (if possible) until theoretical saturation is reached and new cases do not provide any essential new insights into the specific research object and research interests.

Ethnographic field studies often include methodological triangulation: Information on the research object is gathered through different methods from independent data sources in order to increase the validity of the results. Such data-gathering methods can include observation, interviews, and document 
analysis. Through independent analysis by different researchers, an intersubjective account of the data is provided (intercoder reliability).

\section{Cognitive-scientific framework of research}

Sketching the theoretical concepts used to approximate the research object poses a special challenge in the situated, embodied and extended cognition approach, as there is no well-established tradition in translation studies to rely on and no ready-made cognitive scientific models to apply. The situation would be different if we were relying on older, more traditional cognitive science approaches. For example, in the propositional theory of mind (Fodor 1981, Pinker 1997), where cognitive processes are described as linguistically transparent and rule-based symbol manipulation processes, we could apply algorithms to simulate the mental computerization. We could also describe the cognitive structure as semantic networks that include a logical order and definable mental units with specific characteristics. In such a case, abstracting a symbolic representation of the mental processes that are assumed to produce the observed translator behaviour would suffice as an explanation. However, this information-processing view of cognition-with its metaphor of the mind as a computer-seems to fall short as a model of real-life, real-world human cognition. Another well-established and popular line of cognitive science, connectionism, describes cognition as parallel distributed processes of pattern recognition in the neural network of the brain (Rumelhart \& McClelland 1986). The connectionist approach is an essential move towards neurological plausibility in cognitive science, but its sole concentration on mental, internal processes of the brain now seems insufficient in light of the findings of the many cognitive scientific approaches that began to tackle the challenges of "bodies, the world, and dynamic systems" as well as "societies" in the 1980s (Thagard 2005: 191ff). In the course of the subsequent decades, there has been an increasing amount of evidence that body, world, time, and social activity play essential roles as constituent parts of cognitive processes. The approaches developed in this paradigmatic change in cognitive science-e.g., situated, embodied, embedded, dynamic systems and extended cognitionbelong to a group or cluster of several current cognitive scientific approaches with different conceptual frameworks and foci but similar, "broadly compatible" and "loosely united" research interests (Atkinson 2010: 606; see also Clark 1998).

However, these cognitive approaches have not developed established, neatly presented models of cognition that include the factors needed to explain cognitive processes. This is probably due to the fact that not only are they 
themselves still in a relatively early phase of development, but also that the concrete factors which influence cognition in an individual case are, by definition, situation-dependent. If we take the claim seriously that cognition is a distributed process that not only includes the brain, but also the body and the environment of the brain, we will have to decide what parts of the potentially relevant environment need to be taken into account in a specific translation process research study. Should the cultural, ecological, physical, historical, social and other aspects of the environment be included? If so, how should this be done? The observation should potentially include the use of artefacts like information and media infrastructures, architecture and the spatial and geographic context, the biological and ecological environment, as well as the social spaces and the areas of interaction-all in their dynamic, cultural and historical contexts. Obviously, there are project-specific decisions to be made here, since each research endeavour will focus on specific research questions and naturally cannot include the whole complexity of human cognition.

\section{Prior modelling of the research object}

As mentioned above, we need to do some structuring of the research object prior to an empirical inquiry in order to decide on the data sources to be included. In a recent article (Risku, Windhager \& Apfelthaler 2013), my colleagues and I relate the current cognitive science discussion to an integrative approach in the field of social network analysis: We draw from Schweizer's (1996) dynamic network model to include both environmental as well as mental aspects in the analysis, and adapt it for our cognitive translation studies purposes to form a dynamic model of translatorial cognition and action. In the present paper, data acquisition is incorporated and discussed in line with the six aspects differentiated in this adapted model: cognition, action, social network, artefacts, environment, and time.

Cognition refers to self-organizing processes of interconnected sensorimotor sub-networks of the cognitive system (Peschl 2002) and includes all operations that work on internal and external representations with the aim of creating translations, building, for instance, on memorized knowledge (of languages, translation, business, communication and cooperation methods) and including all manner of associations, knowledge and expectations. Action refers to all physical translation activities that involve task-oriented operations and actions as behavioural, observable action patterns. The social network includes all actors with their specific roles in formal and informal networks, along with their relational ties, which often include the coordination of responsibilities and workflow patterns. Artefacts include the material 
and immaterial objects used as tools, such as mental and physical checklists, texts, software and hardware. The translation environments include the source, target, client, and translator activity systems, as perceived and operative from the point of view of the translators or other actors involved in the translation process. They form the ecological, physical, geographic, economic, political, demographic and social boundary conditions of action. Finally, time here refers to the temporal changes and developments in each of the above aspects, their relations and the overall situation. Thus, time is not an independent aspect, but will be discussed as the temporal-historical dimension of the other five.

\section{Data gathering}

In line with this initial structuring of the research object, data were gathered on the following points:

Cognition: This aspect essentially deals with the person and his/her thinking in his/her historical and present context. Which cognitive resources and experiences inspire the person being studied? Where does he/she come from? How did he/she end up in a translation-relevant role? How does he/she see himself/herself? How does he/she feel in that situation? It is to be presumed here that the prior and current education, training, academic background and work experience of the person studied will have an influence on his/her associations, knowledge, expectations, interests, emotions and evaluations.

Action: Given the increasing differentiation and heterogeneity of the tasks performed in the field of translation, this aspect can theoretically include translatorial actions that extend from the translation of certificates, technical texts and literature through to the localisation of video games and the different actions included in terminological research, project management and participation in online discussions.

Social network: In his/her current work processes, an individual translator can be integrated into complex, higher-level processes with complex forms of work distribution, virtualisation and networking. The translation process is increasingly mediated by different people and instruments in an increasingly longer chain and increasingly larger and more complex networks (Buzelin 2005). Target language material (e.g., in the form of glossaries, translation memories, parallel texts and text modules made available by others) provided to the translator or third-party revision processes can strongly impact the final translation. These developments indicate a shift in perspective from the 
individual to a network level, suggesting a need to revise the individualistic concept of "the translator". This project will therefore place an emphasis both on such networks of actors and on the aspect of computer-assisted collaboration, where the negotiation of complex activities and conflicting interests are a daily task.

Artefacts: Artefacts are material and immaterial objects formed and used by humans in cognition. As cognitive scaffolds (Clark 1997), they help and structure thinking by serving, for example, as reminders, retainers and organizing elements. From the theoretical perspective, the fundamental role played by artefacts has been stressed by the common predecessors of the situated, embodied and extended approaches, e.g., in the work of Vygotsky (1986), who emphasizes the social aspect of learning and the way in which adults, peers and experts with their cultural concepts, models and artefacts facilitate and enable cognitive development. Thus, artefacts are not just restricted to modern information and communication software and tools, but also include all the material and immaterial objects we use to avoid having to try to store and process all the relevant information we need in the brain. As current trends indicate, while an increasing use of digital technologies is evident in many fields, including translation, there are still some individual possibilities to deviate from the mainstream: Depending on the paths their lives and work take, people can become data hermits, luxury 'offliners' (who have no access to digital media or consciously reject the use of digital media and participation in digital networks) or indeed couch potatoes or online nomads-who use digital media intensely and participate in digital networks either from home or other locations (Hartmann \& al. 2001).

Environment: The translatorial environment and the client's environment usually form part of the source or target system. However, this does not always have to be the case, since translation projects are frequently outsourced and offshored to distant locations, often for economic reasons. Thus, the physical, geographic, economic and political conditions of action are not self-evident and must be studied on a case by case basis.

\section{The case and its participants}

This project is a further step in an ongoing body of research aimed at establishing a theoretical foundation of an extended view of translation and exploring the methodological choices and decisions to be made. Since my last empirical research project in this area (Risku 2009) included a field study at 
a reasonably large translation agency and dealt mainly with the complexities of translation management and working with numerous clients, agencies and freelance translators, I felt that my next case for scrutiny should be one that was able to extend this picture of translation processes as they can be observed today.

It can be reasonably assumed that a contrasting translational setting would, for example, be one in which a single translator works in direct contact with a client who has written the source text himself/herself. Since my research interest lies not in the achievements and deficits of laypeople or students, but in translators who have demonstrated and achieved a continuously high level of translating performance (Ericsson 2010: 254), the object of study was chosen based on personal recommendations from several independent clients of the translator. These recommendations correspond to "the expert's superior performance" described by Ericsson (2010: 256) in an interpreting context: "If we are primarily interested in the development of elite interpreting performance, it may be necessary to seek out those individuals that have attained an outstanding, reproducible level of interpreting performance", while "it is likely that elite interpreters have studied and practiced interpreting for 10-20 years". The translator observed conforms to these criteria with the exception that she did not study translation; she is an English native speaker who originally studied modern languages (French and German).

In this project, the observation will also not be restricted solely to one person during one phase of the production process, but will instead reconstruct the entire collaborative "making-of" a translation: from the early pre-production phase to the actual work involved in creating the translation and the subsequent post processing. For this reason, I selected a translation project for which the whole "principal-agent dyad" (Abdallah \& Koskinen 2007) of client and translator can be included as research participants.

\section{Data acquisition and preparation}

A combination of interviews and participant observation was used in the data acquisition process. Qualitative, semi-structured interviews served to reconstruct the complete translation process from both the client (a retrospective interview lasting $1 \mathrm{~h} 20 \mathrm{~min}$ ) and the translator perspectives (a retrospective interview lasting $1 \mathrm{~h} 09 \mathrm{~min}$ and several short interviews both prior to and after the observation periods). The interviews were audio-recorded. Two days of participant field observation were carried out to obtain insights into the translation processes carried out by the translator (detailed protocols of day I: $2 \mathrm{~h} 25 \mathrm{~min}$, day II: $2 \mathrm{~h} 25 \mathrm{~min}$; the equal duration of the two observation 
periods is merely a coincidence, yet indicative of the concentrated, continuous working time spans of the translator observed). During the observation, hand-written notes were taken to document the translation process. These notes were then used in the verbal dictation of the observation protocol onto audiotape immediately after each observation period. The interviews and observation periods were protocolled according to GAT conventions (see Selting \& al. 2011).

In the present case, it was not possible to observe the translation process that was the topic of the interviews carried out with the translator and the client. Instead, the translator was observed translating a similar text (a detailed, informative report on the results of a research and development project) in a similar situation (translating for a "direct" client, not for an agency). The target audience for both the reconstructed and the observed translation processes is the international community in a particular field; the language can be categorized as generally understandable, non-technical and non-literary; and the translator is translating from German into English (her mother tongue). Even though the observation period also included other ongoing projects, the results reported here rely solely on the analysis of the cognitive aspects of the original, reconstructed project and the very similar project the translator was working on during the observation.

\section{Data analysis}

The interview and observation protocols were analysed according to the qualitative analysis method proposed by Mayring (2000), which relies on the data-oriented development of themes, categories and patterns. The topics identified in the material were contextualized and the relationships between the topics were analysed. Two researchers independently carried out first data coding and analysis, followed by common coordination sessions in which a consensual categorization was attained, thus providing intercoder reliability. The main actors and tools mentioned by those interviewed and/or observed were documented. The network that became visible in the analysis (from the point of view of the interviewed/observed individuals) was visualized as a simple network graph. The individual relationships were described in writing.

\section{Preliminary results}

Since we are currently still at the stage of analysing the interview and observation protocols, I am only in a position to report on some initial, preliminary results of a striking, palpable nature; their existence as cognitive characteristics 
of the research object appears quite evident right from the first analyses. Likewise, since we are still working on the implications of the analysis and seeking to obtain an overview of the complex, heterogeneous dynamics involved, I can only offer a brief glimpse at some of the results on different levels, without integrating them at this stage into a single system or model. By necessity, less attention will be paid in this article to other data gathered; the relevant environments (physical, geographic, economic and political conditions of action) and the personal histories of the actors involved, for example, will not be addressed in any kind of detail in this paper. However, there are three phenomena which I can already mention with a fairly high degree of reliability. These are described briefly below from the macro to the micro-level of the activity system analysed: (1) network complexity; (2) interactionreconfiguring the cognitive space; and (3) iterative operation patterns.

\subsection{Network complexity}

From the social network perspective, this case could be presumed to exhibit characteristics of the classic single principal-agent dyad, not a complex multi-node network. After all, a "classic" case of a single translator working directly for a client-author was deliberately chosen as the smallest translatory

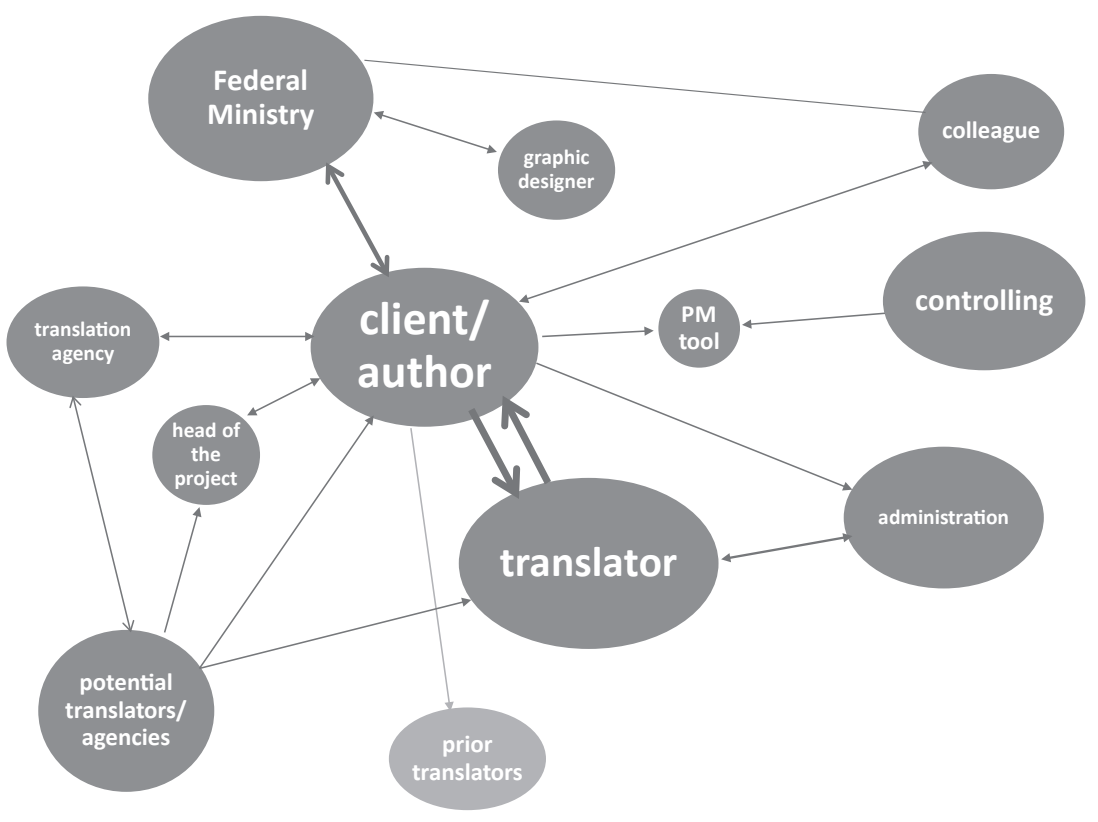

Figure 1. The client / author network. 
project unit. Such units are supposed to be relatively independent in their mutual negotiation of project conditions, i.e., without intermediaries (Abdallah 2012: 46). However, it was strikingly apparent that the translation project actually involved a whole network of actors and tools, both on the client and on the translator side. To exemplify this point, let us take a closer look at the client network.

The client acted as one node in a project-relevant network with several other actors and environmental constraints (see figure 1). The (ego-) network that became visible here included (in order of appearance in the project):

- the sponsor/contractor of the research and development project (and via the sponsor/contractor, the graphic designer) who financed the project, including dissemination (of which the translation formed a part),

- the head of the research and development project (to whom the client himself reported),

- the project management tool (and via the tool, the controlling department in the client's organization) as the project handbook in which he documented the contents of the project, hours worked, correspondence, and monthly financial reports,

- prior translators and the client's cooperation experience with these translators,

- the translator, translation agencies and other freelancers considered as potential translators for the project,

- an administrative unit in the client's organization to whom he forwarded information on the translator and the project to enable them to draw up the necessary contract,

- a translation agency which had been commissioned for another translation for the same organization, but for another client and project,

- a colleague of the client who was asked to revise the translation and whose overwhelming revisions were completely ignored by the client (with reference to their low quality).

The client was very aware of the influence of these actors and tools on the project and its end product.

\section{2. Interaction: Reconfiguring the cognitive space}

The translator's workplace is set up with all the necessary tools at hand around her (quite literally "around" her, on all four sides of her seat, see 
figure 2): From right to left, she has her mobile phone, two screens (each with a specific function), a keyboard in front of them, a pile of notepaper and a pen between the screens (behind the keyboard), an iPad, a printer, files and folders, various books and dictionaries and a shredder. There are only a couple of books on the desk (e.g., on English style, a parallel text); most other translation-related books (e.g., dictionaries, grammar books, etc.) are stored in a bookcase directly behind her seat, but none of these were used during the observation period.

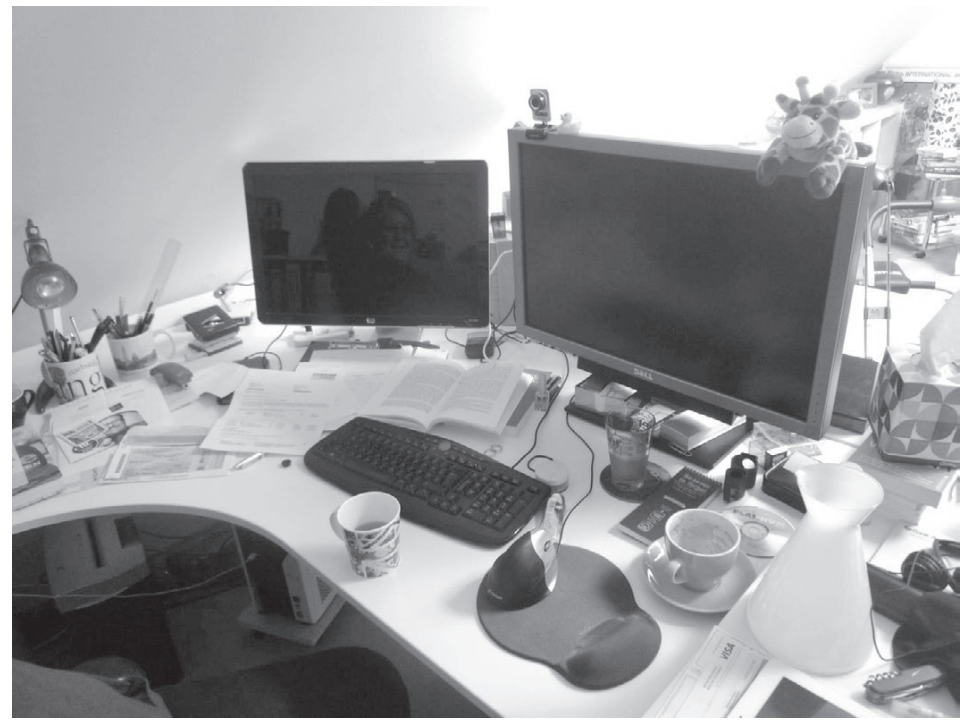

Figure 2. The front part of the translator's workplace (the Union Jack coffee cup was only placed on the desk after the observed working period).

The translator leans on external (in the sense of non-mental) and, probably more interestingly, externalized resources in several ways. For example, as external resources, she uses

- the source text (which she reads through in its entirety and then translates from the beginning to the end),

- online dictionaries ("for inspiration"),

- online parallel texts (mainly to check correct usage of terminology), and

- prior translations she has done herself (to maintain consistency with prior solutions). 
The use of these external resources was observed and noted during the workplace observation, and their role in the translation process was described by the translator in the retrospective interviews.

In addition, the translator showed a clear tendency to externalize a part of the process and thus transform the internal processing into an interaction with self-produced outer stimuli. For example,

a. She wrote down a term found in a parallel text on a piece of paper to have it to hand for subsequent use in the current translation, only to throw the piece of paper away afterwards. This way, she changed the task from trying to remember a term to using external memory aids.

b. She repeatedly wrote a draft translation of (part of) a sentence, which she then went back to and changed immediately after she had written it. Thus, she did not first formulate a satisfying, sufficiently adequate (part) sentence in her head and then write it down, but preferred to first write a rough initial suggestion and only then formulate the sufficient solution by manipulating the already externalized words and utterances.

c. After translating a couple of further sentences, she read and revised this sentence again. Given the types of revisions she made, for example, adding context, improving the style, and adding the word Austrian (which was not necessary for the source text readers, but is needed for the target text readers), it would seem that she was then mainly looking at the translation as an independent text from the target reader perspective. In doing so, she seemed to write a second version of the target text and changed her task from writing to editing.

d. Repeatedly, while reading some paragraphs of her translation immediately after writing them, and without writing or correcting anything, she moved the cursor back and forth, up and down, pointing to the area of interest and following her gaze. In this way, she changed the task from keeping track of the flow of text to following the cursor.

e. After writing several paragraphs, she changed her sitting position, took her hands off the keyboard and mumbled the last translated paragraphs half loud to herself, sometimes quickly correcting a point or two. When asked about this mumbling in a retrospective interview, she said that she usually does that in order to "hear what the translation sounds like". On the one hand, through this repeatedly observed pattern, she generated a break (a turning point) to mark a closing of a task, and on the other hand, she produced outer stimuli to avoid 
purely internal processing-she could then actually hear what the translation sounded like instead of just trying to imagine it.

The above externalizations demonstrate interaction loops that clearly consist of cognition, action, use of artefacts and environmental organization-epistemic actions that serve thinking and change the nature of our tasks (Kirsh \& Maglio 1994). As Clark (1997:207) notes, public speech and inner rehearsal are typical tools for changing the type of task from mental processing to interaction with the environment and thus reconfiguring the cognitive space.

\subsection{Iterative operation patterns}

During the planning activities, the text preparation, and the parallel production and revision of the translation, there were several observable, iterative, regular patterns that stand out as behavioural and cognitive routines in the way the translator works. Two main processes can be clearly distinguished. The first of these is the fluent alternating of her attention in line with certain iterative patterns between information resources on the left screen and writing the translation on the right screen (copy and paste of source and target text terms from right to left and left to right, searching in online resources in a specific, typical order on the left screen, etc.). The second process takes place within the production and processing of the translation on the right screen. Typical routines observed here include, for example,

a. repetitions of the sequence of "writing, rewriting;"

b. after completing 1-2 paragraphs, repetitions of the sequence of "reading, rewriting, adding context;"

c. changing sitting position, leaning forward, repetitions of the sequence of "mumbling, rewriting;"

d. deleting the source text passage translated, changing sitting position and marking the completed work both physically and with a verbal or para-verbal utterance like done! or phew!

In view of the above mentioned findings, it seems that the usual description of different mental problem-solving patterns in translation process research could be complemented with the description of such cognitive interaction patterns. On the one hand, this would emphasize the role of fluent interaction in translation, whereas translation process research has traditionally strongly concentrated on the strategies translators use when encountered with explicit or implicit translation "problems" (causing, e.g., pauses or problem verbalizations; see also Muñoz 2010). On the other hand, it would avoid 
the expectation in translation process research that all the remembering, processing, and monitoring is done in the head, since major parts of this seem to be shifted to bodily movements, spatial organization, and interaction with artefacts.

\section{The socio-cognitive extension to translation process research}

One aspect that surprised me in the initial results from this project was the complexity of the networks on both sides, i.e., on the side of the client and on the side of the translator. In my search for the smallest possible unit with a minimum number of process participants, I had chosen a dyad and ended up with complex full-grown interactive networks. The other two distinctive phenomena observed, interaction (reconfiguring the cognitive space), and iterative operation patterns, however, confirmed the theoretical assumptions: They seem to be symptomatic of the social embeddedness of cognition and of the human tendencies to externalize mental processes, shift cognitive processing load to external aids and transform mental processes to interaction between embodied action and artefacts. As Clark (1997:207) says, "Again and again we trade culturally achieved representation against individual computation".

All in all, our dynamic model of translatorial cognition and action (Risku, Windhager \& Apfelthaler 2013) was crucial in allowing us to model the object of interest and design the data acquisition and analysis in a way that revealed the above mentioned phenomena. The fact that the ongoing research project takes the situated, embedded and extended cognitive scientific approaches as its basis provides a double extension to mainstream translation process research in its methodological design. On the one hand, the concept of the translation process itself is widened. The process is defined as starting with the decision to have something translated and ending when the translation is approved and paid, last contacts in the project are completed and the translation is made available in the target setting. All through this process, decisions are made that depend on the cognitive processes in the different interactive situations and influence the final outlook of the translation. On the other hand, the scope of cognitive research to translation is widened from mental to socio-cognitive aspects, including the social and artefact-mediated processes that form part of cognition-the whole system that constitutes human intelligence (Clark 2008). These extensions might help us conceptualize translation in a broader sense and avoid ahistorical, reductionist fallacies. Since a research project can always only describe a part of the complex socio-cognitive dynamics involved in translation, opening 
the map to include socio-cognitive processes might be helpful in pinpointing which part and which aspect of which sub-process we are taking a closer look at in a given research project.

\section{References}

AbDallaH, Kristiina. (2012) Translators in Production Networks. Reflections on Agency, Quality and Ethics. Joensuu: University of Eastern Finland.

ABDAlLAH, Kristiina. (2010) "Translators' agency in production networks." In: Kinnunen, Tuija \& Kaisa Koskinen (eds.) 2010. Translator's Agency. Tampere: Tampere University Press, pp. 11-46.

ABDAllaH, Kristiina \& Kaisa Koskinen. (2007) "Managing trust: Translating and the network economy." Meta 52:4, pp. 673-687. DOI 10.7202/017692ar.

ATKINSON, Dwight. (2010) "Extended, embodied cognition and second language acquisition." Applied Linguistics 31:5, pp. 599-622. DOI 10.1093/applin/ amq009.

BuzELin, Hélène. (2005) "Unexpected allies: How Latour's network theory could complement Bourdieusian analyses in translation studies." The Translator 11:2, pp. 193-218.

Chesterman, Andrew. (2009) "The name and nature of translator studies." Hermes 42, pp. 13-22. Electronic version available at: <http://download2. hermes.asb.dk/archive/download/hermes-42-2-chesterman_net.pdf> on 19 March 2013.

Clark, Andy. (1997) Being There: Putting brain, body, and world together again. Cambridge, MA: The MIT Press.

Clark, Andy. (1998) "Embodied, situated, and distributed cognition." In: Bechtel, William \& George Graham (eds.) 1998. A Companion to Cognitive Science. Malden, MA: Blackwell, pp. 506-517.

Clark, Andy. (2008) Supersizing the Mind: Embodiment, Action, and Cognitive Extension. Oxford: Oxford University Press.

Clark, Andy \& David J. Chalmers. (1998) "The extended mind." Analysis 58/1: 7-19. Electronic version available at: <http://consc.net/papers/extended. html> on 19 March 2013.

ELMAN, Jeffrey L. (1994) "Learning and development in neural networks: The importance of starting small." Cognition 48, pp. 71-99. Electronic version available at: $<$ http://www.cs.swarthmore.edu/ meeden/DevelopmentalRobotics/elman_cognition1993.pdf> on 19 March 2013.

ERICSSON, K. Anders. (2010) "Expertise in interpreting: An expert-performance perspective." In: Shreve, Gregory M. \& Erik Angelone (eds.) 2010. Translation and Cognition. Amsterdam: Benjamins, pp. 231-262 (reprint of Ericsson, 
K. Anders (2000) "Expertise in Interpreting: An expert-performance perspective." Interpreting 5:2, pp. 187-220).

FODOR, Jerry A. (1981) Representations: Philosophical Essays on the Foundations of Cognitive Science. Cambridge, Massachusetts: The MIT Press.

GARFINKEL, Harold. (2002) Ethnomethodology's Program. New York: Rowman and Littlefield.

Glaser, Barney G. \& Anselm L. Strauss. (1967) The Discovery of Grounded Theory. Strategies for Qualitative Research. Hawthorne, NY: Aldine de Gruyter.

Hartmann, Monika; Andreas Heigl \& Martin Katheder. (2001) Trendbook 2001: Volkswirtschaft. München: Hypovereinsbank.

HofFMAN-RiEM, Christa. (1980) "Die Sozialforschung einer interpretativen Soziologie - Der Datengewinn." Kölner Zeitschrift für Soziologie und Sozialpsychologie KZfSS 32, pp. 339-372.

Hutchins, Edwin. (2010) "Cognitive ecology." Topics in Cognitive Science 2:4, pp. 705-715. DOI 10.1111/j.1756-8765.2010.01089.x.

KIRSH, David \& Paul P. Maglio. (1994) "On distinguishing epistemic from pragmatic action." Cognitive Science 18:4, pp. 513-549. DOI 10.1207/ s15516709cog1804_1.

MARTín DE LEÓn, Celia. (2013) "Who cares if the cat is on the mat? Contributions of cognitive models of meaning to Translation.” In: Rojo López, Ana María \& Iraide Ibarretxe-Antuñano (eds.) 2013 Cognitive Linguistics and Translation. Advances in Some Theoretical Models and Applications. Berlin: De Gruyter Mouton, pp. 99-122.

MaYring, Philipp. (2000) Qualitative Inhaltsanalyse. Grundlagen und Techniken (7. Auflage). Weinheim: Deutscher Studien Verlag.

MuÑoz MARTín, Ricardo. (2010) "Leave no stone unturned. On the development of cognitive translatology." TIS Translation and Interpreting Studies 5:2, pp. 145-162. DOI 10.1075/tis.5.2.01mun.

MuÑOz MARTín, Ricardo. (2013) "More than a way with words: The interface between Cognitive Linguistics and Cognitive Translatology." In: Rojo López, Ana María \& Iraide Ibarretxe-Antuñano (eds.) 2013 Cognitive Linguistics and Translation. Advances in Some Theoretical Models and Applications, pp. 75-94.

PESCHL, Franz-Markus. (2002) "Elaborarea teoriilor în stiintele cognitiei. Sintetizarea si construirea modelelor cognitive" [Theory development in cognitive science]. In: Botez, Angela \& Bogdan M. Popescu (eds.) 2002. Filosofia constiintei si stiintele cognitive. Bucureşti: Cartea Românească, pp. 473-491.

Pinker, Steven. (1997) How the Mind Works. New York: W. W. Norton \& Company. RISKU, Hanna. (2009) Translationsmanagement. Interkulturelle Fachkommunikation im Informationszeitalter. 2. bearbeitete Auflage. Tübingen: Gunter Narr. 
RISKU, Hanna. (2010) "A cognitive scientific view on technical communication and translation: Do embodiment and situatedness really make a difference?" Target 22:1, pp. 94-111.

RISKU, Hanna; Florian Windhager \& Matthias Apfelthaler. (2013) "A dynamic network model of translatorial cognition and action." Translation Spaces 2, pp. 151-182.

RISKU, Hanna \& Angela Dickinson. (2009) "Translators as networkers: The role of virtual communities." Hermes 42, pp. 49-70. Electronic version available at: <http://download2.hermes.asb.dk/archive/download/Hermes42-4-risku\&dickinson_net.pdf> on 18 March 2013.

Rumelhart, David E. \& James L. McClelland (eds.) (1986) Parallel Distributed Processing. Explorations in the Microstructure of Cognition. Volume 1: Foundations. Cambridge, MA: The MIT Press.

SCHWEIZER, Thomas. (1996) Muster sozialer Ordnung: Netzwerkanalyse als Fundament der Sozialethnologie. Berlin: D. Reimer.

SElting, Margret; Peter Auer; Birgit Barden; Jörg Bergmann; Elizabeth Couper-Kuhlen; Susanne Günthner; Christoph Meier; Uta Quasthoff; Peter Schlobinski \& Susanne Uhmann. (2011) "A system for transcribing talk-in-interaction: GAT 2" (Translated and adapted for English by Elizabeth Couper-Kuhlen and Dagmar Barth-Weingarten). Gesprächsforschung - Online-Zeitschrift zur verbalen Interaktion 12, pp. 1-51. Electronic version available at: <http://www. gespraechsforschung-ozs.de/heft2011/px-gat2-englisch.pdf> on 18 March 2013. ISSN 16171837.

Suchman, Lucy (2007) Human-Machine Reconfigurations. Plans and Situated Actions. Cambridge: Cambridge University Press. DOI: 10.1111/j.14684446.2007.00173_12.x.

THAGARD, Paul. (2005) Mind. Introduction to Cognitive Science. 2nd edition. Cambridge, MA: The MIT Press.

VyGotSky, Lev Semenovich. 1986. Thought and Language (translation newly revised and edited by A. Kozulin). Cambridge, MA: MIT Press.

\section{BIONOTE / KURZVITA}

Hanna Risku is Professor for Translation Studies at the Department for Translation Studies at the University of Graz, Austria, and co-editor of Fachsprache - International Journal for Specialized Communication. Her previous positions include full professor for Applied Cognitive Science and Technical Communication, Head of the Department for Knowledge and Communication Management and Vice Rector at the Danube University Krems, Austria, guest professor at the University of Aarhus, Denmark, and lecturer at different 
universities in Austria, Finland, Spain and Sweden. She studied at the University of Tampere, Finland, and at the University of Vienna, Austria. Her research areas include cognitive scientific foundations of translation, situated cognition, usability, knowledge management, transcultural communication, and translation as computer-supported cooperative work.

Hanna Risku ist Universitätsprofessorin für Translationswissenschaft am Institut für theoretische und angewandte Translationswissenschaft (ITAT) an der Karl-Franzens-Universität Graz, Österreich. Sie ist Mitherausgeberin von Fachsprache - International Journal of Specialized Communication. Davor war sie Universitätsprofessorin für Angewandte Kognitionswissenschaft und Technische Kommunikation, Leiterin des Departments für Wissens- und Kommunikationsmanagement sowie Vizerektorin an der Donau-Universität Krems, Österreich. Zudem war sie als Lektorin an verschiedenen Universitäten in Finnland, Österreich, Schweden und Spanien tätig. Forschungsschwerpunkte: Kognitionswissenschaftliche Aspekte der Translation, Situated Cognition, Usability, Wissensmanagement, Transkulturelle Kommunikation und Translation als Computer-Supported Cooperative Work. 